\title{
Betanin: A Bioeconomy Insight into a Valued Betacyanin
}

\section{Rosaria Ciriminna ${ }^{a}$, Carmelo Danzì ${ }^{b}$, Alexandra Fidalgo ${ }^{c}$, Giuseppe Timpanaro ${ }^{b}$, Laura M. Ilharco *c , Mario Pagliaro *a}

${ }^{a}$ Istituto per lo Studio dei Materiali Nanostrutturati, CNR, via U. La Malfa 153, 90146 Palermo, Italy; ${ }^{b}$ Dipartimento di Agricoltura, Alimentazione e Ambiente, Università degli Studi di Catania, via Santa Sofia 100, 95123 Catania, Italy; ${ }^{\circ}$ Centro de Química-Física Molecular and IN-Institute of Nanoscience and Nanotechnology, Instituto Superior Técnico, Universidade de Lisboa, Av. Rovisco Pais 1, 1049-001 Lisboa, Portugal

\begin{abstract}
Sourced so far mostly from beet root juice, betanin is a red-violet natural colorant increasingly used by the food, beverage and nutraceutical industries. We provide an updated bioeconomy perspective into a valued betacyanin whose supply and applications, we argue in this study, will rapidly expand.
\end{abstract}

Keywords: betanin; natural red; pigment; betalain; Opuntia; beet root

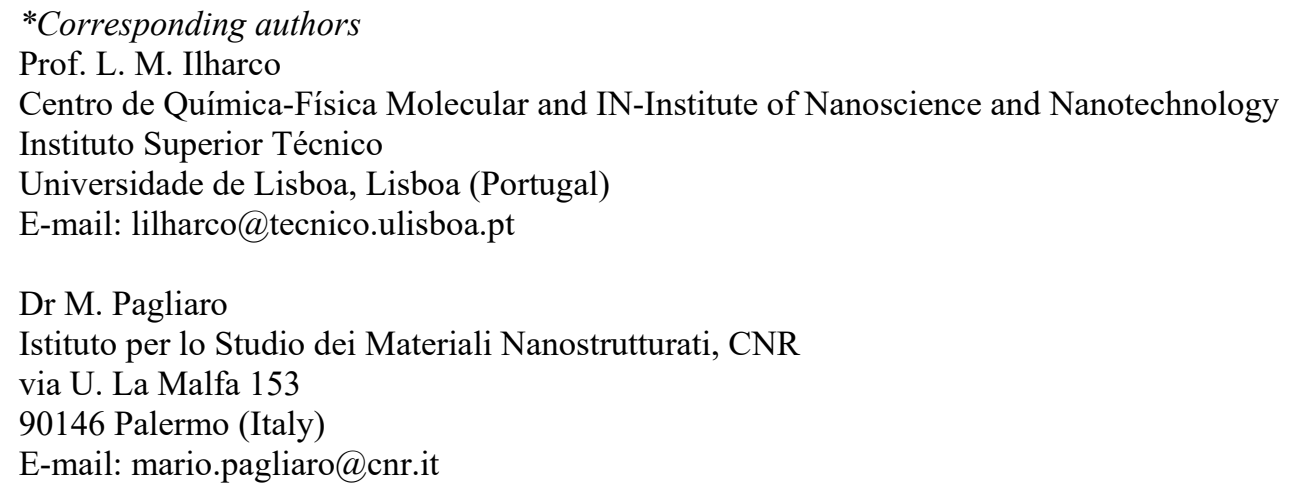




\section{Introduction}

Lately re-evaluated and re-approved as food additive in the European Union (labelled E162), ${ }^{1}$ betanin (betanidin-5-O- $\beta$-glucoside) is a red-violet betalain widely used as food colorant and, more recently, also as antioxidant dietary supplement. Betalains are watersoluble natural pigments containing betalamic acid (the chromophore) which conjugates either with cyclo-3,4-dihydroxyphenylalanine (DOPA) to produce the red-violet betacyanins, or with different amino acids or amines to afford yellow-orange betaxanthins. $^{2}$

Added to food and beverage products (for example at $0.5 \%$ level in ice creams) betanin-based extracts impart a striking red color without altering the flavor, whereas the pigment stability between $\mathrm{pH} 3$ and 7 makes its use particularly attractive for the food industry transitioning from synthetic to natural colorants. In 2007, indeed, scholars in psychology and child health in the UK published the outcomes of randomised, doubleblinded, placebo-controlled trial on artificial food additives and hyperactive behaviour in 300 children aged three or eight/nine. ${ }^{3}$ Findings revealed a significant increase hyperactive behaviour, including impulsive behaviour and loss of concentration, in children in both age groups. This led the UK Food Standards Agency (which had funded their study) recommending food and beverage manufacturers voluntary removal of six artificial colourings, which are the six main food and beverage synthetic colorants (allura red, E129; ponceau 4R, E124; tartrazine, E102; sunset yellow, E110; quinoline yellow, E104; and carmoisine, E102). ${ }^{4}$ Following deliberation of the EU Parliament in $2008,{ }^{5}$ in 2010 the European Commission required food and beverage manufacturers to insert the warning "may have an adverse effect on activity and attention in children" on the label of beverage and foodstuff products containing one of the six food color additives linked to hyperactivity in children. 
As threatening as it may sound for European consumers, in a thorough recent account on betalain as natural colorants, ${ }^{6}$ Ferreira and co-workers emphasized how several food colorants that are allowed in the European Union by the Council regulation (EC) 1129/2011, including Carmoisine (E122), Amaranth (E123) and Ponceau 4R (E124), are no longer permitted in the United States. This spurred industry's interest for natural colorants, and in particular for those capable, likewise to lycopene, ${ }^{7}$ to synergistically provide color and health benefits.

Reviewing the impact of extraction and processing conditions on betalains and comparison of properties with anthocyanins, scholars in Canada lately reported how information about the effects of processing on their physicochemical properties and stability is scattered. ${ }^{8}$ This study provides an unified and updated bioeconomy perspective on betanin aimed at bioeconomy scholars and practitioners. 


\section{Production, purification and emerging applications}

The betanin molecule has a high molar extinction coefficient $\varepsilon=6.56 \times 10^{4} \mathrm{~L} \mathrm{~mol}^{-1} \mathrm{~cm}^{-1}$ in the visible region, and the spectrophotometric method to quantify it in solution via the Beer's law taking into account light absorption at the wavelength then considered of maximum absorption ( $530 \mathrm{~nm}$ ) was described as early as of 1938 (today's value for $\lambda_{\max }=$ $536 \mathrm{~nm}) .{ }^{9}$ Recently, scholars in Egypt introduced the use of betanin as a novel colorimetric sensor for the naked eye detection of copper ions in water samples, providing a fast and low-cost colorimetric determination of $\mathrm{Cu}^{2+}$ ions simply based on the coordination between the copper ion and betanin dye which leads to a large change in absorbance intensity (Figure 1). ${ }^{10}$
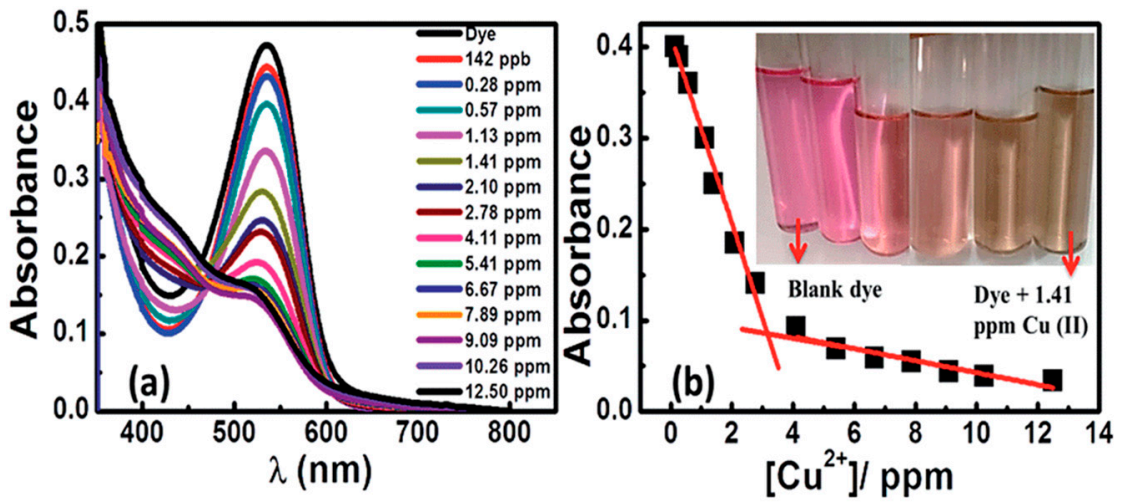

Figure 1. (a) UV-Vis spectrum of betanin extract at $\mathrm{pH} 7$ with additions of $\mathrm{Cu}^{2+}$ ions. (b) The relation between absorbance intensity and $\mathrm{Cu}^{2+}$ ion concentrations [Reproduced from Ref.10, with kind permission].

Betanin shows excellent anti-radical activity thanks both to the good electron donor properties of its two main molecular moieties (betalamic acid and DOPA), and to their strong electronic conjugation. Its high free radical-scavenging activity is associated with the ability to act as hydrogen and electron donator, which is particularly high at neutral and basic $\mathrm{pH}$, namely going from the cationic form to mono-, di- and tri-deprotonated species present in increasingly basic solution (Figure 2$).{ }^{11}$ 

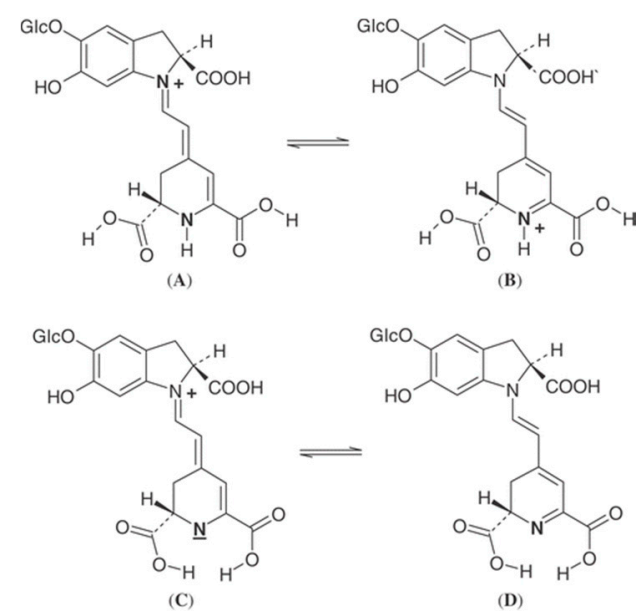

Figure 2. Resonance structures of betanin in cationic state $(\mathbf{A}, \mathbf{B})$ and in $16 \mathrm{~N}^{-}$ deprotonated form $(\mathbf{C}, \mathbf{D})$. [Reproduced from Ref.11, with kind permission]

Present in many plants, fruits and flowers, betanin shows also distinctive biological activity, which includes scavenging of reactive oxygen species, gene-regulatory activity, enzyme-induced and antioxidant defense, as well as in the prevention of LDL oxidation and DNA damage. ${ }^{12}$ At neutral $\mathrm{pH}$ and depending on their concentration, betanin exhibits a stimulating and inhibitory effect on the chlorination activity of the heme enzyme myeloperoxidase (producing cytotoxic $\mathrm{HOCl}$ from $\mathrm{H}_{2} \mathrm{O}_{2}$ and chloride) thereby acting as modulator in all inflammatory conditions mediated by $\mathrm{HOCl}^{13}$

Following numerous studies in the previous decade, in 1980 Harmer, an industrial chemist at a food company, published a first comprehensive study on the occurrence and chemistry of betanin in light of food colouring applications. ${ }^{14}$ Betanin was reported to be stable (bluish-red color) between $\mathrm{pH} 3$ and 7, a very broad $\mathrm{pH}$ range, turning to yellowbrown only at basic $\mathrm{pH}$.

Water also found to promote degradation which is due to hydrolysis (favoured at higher $\mathrm{pH}$ ) of the aldimine bond between betalamic acid and DOPA. The other molecular degradation mechanisms, favoured at lower $\mathrm{pH}$, include decarboxylation and dehydrogenation (Figure 3). 


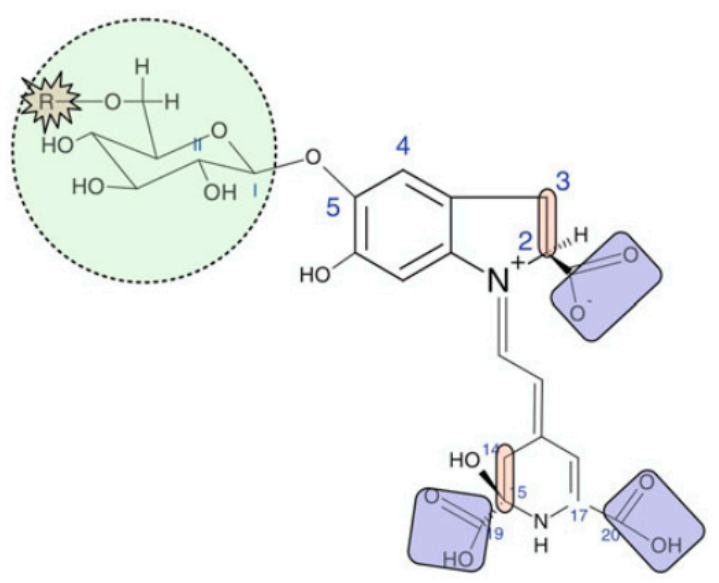

Figure 3. Functional groups prone to degradation in betacyanins: decarboxylation (violet), dehydrogenation (pink), and deglycosylation (green).

[Reproduced from Ref.15, with kind permission].

The hydrolysis degradation mechanism explains why red beet (and cactus pear) whole extracts, which contain high levels of pectins, are considerably more stable than purified beet pigments. ${ }^{15}$ Pectin hydrocolloid indeed lowers water activity (a similar beneficial effects is exploited to stabilize anthocyanins). ${ }^{16}$

Heating, air and light also cause change of the red color to light brown. The temperature dependence of color degradation follows a first order degradation kinetics governed by the Arrhenius equation (Figure 4). ${ }^{17}$

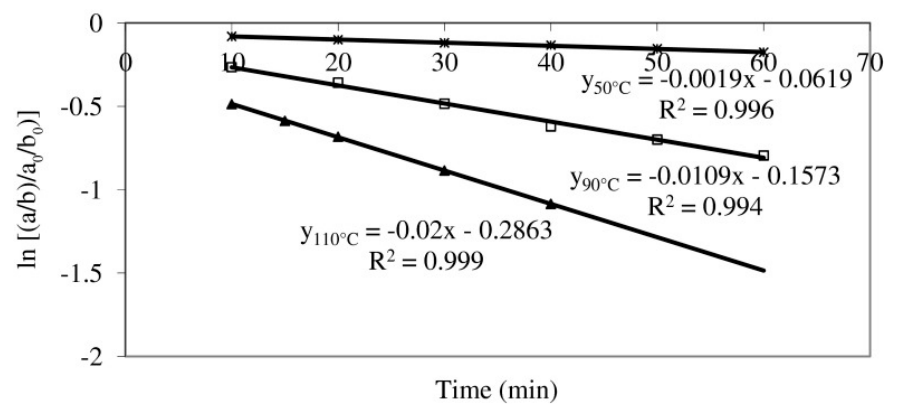

Figure 4. First order plot of color (Hunter 'a/b') degradation in beet root puree at 50, 90 and $120^{\circ} \mathrm{C}$. [Reproduced from Ref.17, with kind permission]. 
It is known since the early 1970s that betanin heat degradation can be significantly slowed down by the addition of $1 \%$ citric acid which acts also as preservant of the color stability, by chelating metal ions, among which iron is particularly prone to decompose the betacyanin. Eventually, in 2006, Stintzing and co-workers reported that the addition of a similar amount of ascorbic acid (Vitamin C) to the betalain extract obtained from the purple pitaya fruit results in even better stabilization of the pigment against heat, eventually making it suitable for food colouring. ${ }^{18}$

In industry, the extraction of betanin is carried out via conventional solid-liquid extraction from beet juice or root macerates using water as extraction solvent at room temperature. The beet roots are pressed, typically in the presence of citric acid, ultrafiltered to concentrate, and pasteurized.

The extracts thereby obtained contain $0.5-1 \%$ of betanin along with a small quantity of yellow vulgaxanthin and significant amounts of sugars and other compounds. The enzymes present in the extract, such as for example polyphenoloxidases (PPOs), also play an important role as shown, for example, by freeze-drying the beet root juice immediately after its extraction (initial $\mathrm{pH}$ 6) which results in browning due to the increase in the concentration of PPOs catalyzing the oxidation of $o$-hydroquinones to $o$ quinones (which polymerise producing brown and red pigments related to fruit browning). ${ }^{19}$

In industry the beet root juice is also spray-dried onto a carrier like maltodextrin where the final betanin percentage is about $0.3-0.5 \% .{ }^{20}$ Eventually, along with fresh beet root juice, commercial lyophilised (freeze-dried) beet root, and commercial betanin diluted with dextrin are the main betalainic commercial sources. ${ }^{21}$ Another important factor responsible for enhanced stability of betalains (Figure 5) is the concentration of the pigment molecule itself, as observed in the case of betacyanins extracted from Opuntia fruits. $^{22}$ 
Attempts to obtain extracts of high betalainic concentration from aqueous extracts containing betalains in low amount via chromatography on preparative scale go back to the early 1980s using macroreticular, cross-linked, nonionic resin adsorbent so that the betanin pigment concentrates on the adsorbent, followed by eluting the adsorbent to remove the betanin pigment. $^{23}$

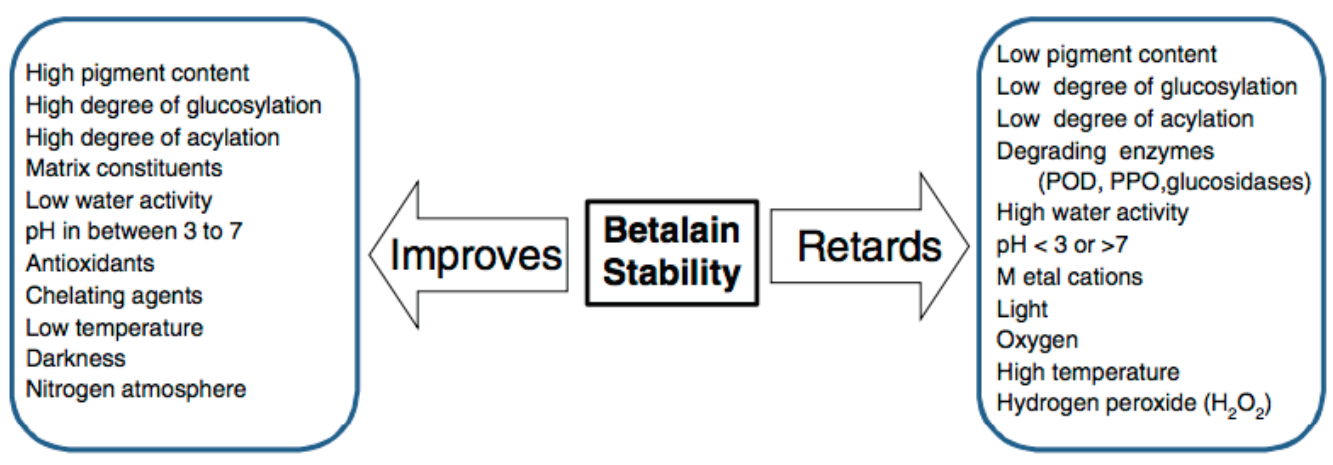

Figure 5. Factors affecting the stability of betalains [Reproduced from Ref.15, with kind permission].

An important progress was reported in 2008, introducing hydrophobic adsorbent in which betalains will associate with the organically modified resin via "pi-stacking" while allowing undesirable compounds to pass. ${ }^{24}$ Remarkably, the nutritional profile of such a pigment-enriched $(41 \%$ betalain) beet root extract is significantly richer than a conventional extract obtained via simple extraction in water, as it contains also a large number of nutritionally important compounds such as Vitamin C, non protein nitrogen, tryptophan and numerous minerals. ${ }^{25}$

Indeed, the latter beet root betalain-enriched extract (tradenamed Racerunner) supplemented to thirteen competitive male runners in two double-blind, cross-over, randomized trials (BRC and control) led to significantly improved exercise performance (3\% lower heart rate, $15 \%$ lower rate of perceived exertion, and a $14 \%$ lower blood lactate concentration compared to the control). ${ }^{26}$ In 2010, a group of researchers from Poland found that individuals consuming betalain-rich extract (35-100 mg capsules, twice daily 
for 10 days) experienced a clar reduction of discomfort (joint pain) associated with osteoarthritis. ${ }^{27}$ Six years later, new evidence showed that consuming beet root juice before strenuous sporting enhances performance and shortens the recovery time. ${ }^{28}$

Comparing seven different methods to purify betanin in fresh bee troot juice, foodgrade beet root powder and betanin standard diluted in dextrin, in 2012 scholars in Brazil demonstrated that food-grade beet root powder had the largest amount of violet-red impurities, likely formed during processing. ${ }^{29}$ In further detail, the team proved that even though ion-exchange chromatography is the best method to separate betanin from its epimer isobetanin, both reverse-phase HPLC and column chromatography provide excellent separation at much higher speed.

Today, improvements in processing and extraction techniques as well as in storage conditions enable the production of betalain pigments of enhanced stability, resulting in commercial betanin extracts having shelf life of 2 years, stored in tightly closed container kept away from heat and sunlight. The degradation induced by light, indeed, in enhanced in the presence of oxygen, ${ }^{30}$ making possible to reduce light-induced degradation by addition of ascorbic acid at levels of $0.1-1.0 \%{ }^{31}$

Based on these advances and on further innovation in separation technology in mid 2016 a food colorant company in the US launched the first heat stable betanin-based food colorant capable retain its vibrant red color even at the high cooking temperature of baking goods. ${ }^{32}$ The new purification technology leads to a purified betanin vegetable juice (tradenamed SupraRed) which avoids the unwanted Maillard reaction causing browning and affecting color. Available in both liquid form and powder form, the product contains beet juice, maltodextrin, citric acid and ascorbic acid only. ${ }^{33}$ 


\section{Emerging sources and extraction technologies}

The conventional betanin extraction process is not efficient, yet chemical degradation is minimized. Recent research efforts applying innovative techniques such as microwaveassisted extraction (MAE) lead to dramatically enhanced extraction yields (Figure 6).

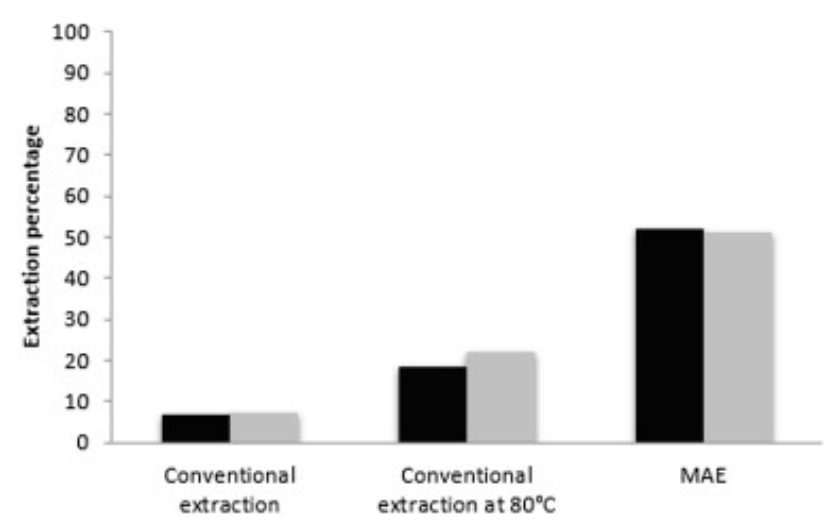

Figure 6. Extraction percentage from maximum extractable pigment of betanins (black) and betaxanthins (gray) obtained with three different methods.

[Reproduced from Ref.35, with kind permission].

For example, a two-step MAE process affords extraction percentages higher than $50 \%$ of the maximum extractable pigments, whereas the amount of pigments extracted with ethanol:water $(1: 1)$ at $23{ }^{\circ} \mathrm{C}$ or at at $80{ }^{\circ} \mathrm{C}$ were considerably lower $(10-20 \%) .{ }^{34}$

More recently, an even higher extraction yield $(83 \%$ of maximum extractable pigment) was obtained from cactus pear using compressed $\mathrm{CO}_{2}$-assisted extraction. ${ }^{35}$ Likewise to commercial betanin extract from beet root, the latter Opuntia spp. extract presented high colour strength, with a total colour difference $\Delta E$ of 8.4 with respect to the red beet extract from which thus it is easily distinguished, whereas the colour in Opuntia spp. fruit extract was the reddest colourant.

The team went further and used the color parameters recommended by the Commission International de L'Eclariage to determine the color coordinates $L^{*}$ (luminosity, from black to white), $a^{*}$ (coordinate from red to green), and $b^{*}$ (coordinate from yellow to blue). Due to their red colour both Opuntia spp. and Beta vulgaris L. extracts had positive $a^{*}$ values, whereas the $b^{*}$ parameter showed greater dispersion in the 
Opuntia extract reflecting more yellowness colour than blueness (Table 1). Dutarte and co-workers concluded that Opuntia spp. fruit extract is a promising natural betalain food colourant.

Table 1 Colour properties of the produced Opuntia spp. fruit extract and the commercial red beet concentrate. [Reproduced from Ref.35, with kind permission].

\begin{tabular}{llllllllll}
\hline & & \multicolumn{1}{l}{ Colour parameters } \\
\cline { 2 - 9 } Opuntia spp. fruit extract & 5.0 & $\boldsymbol{L}^{*}$ & $\boldsymbol{a}^{*}$ & $\boldsymbol{b}^{*}$ & $\boldsymbol{C}^{*}$ & $\boldsymbol{h}^{\circ}$ & $\boldsymbol{\Delta} \boldsymbol{E}^{*}$ & $\mathbf{R G B}$ colour \\
\cline { 2 - 9 } Red beet concentrate & 5.2 & 28.7 & 62.4 & 24.6 & 67.1 & 0.38 & 0.0 & \\
\hline
\end{tabular}

$C^{\star}($ chroma $)=$ saturation of color $h^{\circ}$ (hue angle $)=$ chromatic perceived color determined by the wavelength

In 2005, Stintzing and co-workers in Germany were the first to demonstrate the feasibility of betalain extraction from the fruits of Opuntia ficus-indica (OFI) for food colouring purposes as a viable alternative to red beet. ${ }^{36}$ Obtained directly on a pilot plant scale starting from $20 \mathrm{~kg}$ of fruit, the red and yellow extracts obtained from red and yellow OFI fruits grown in Sicily, neither exhibited negative sensorial impact nor high nitrate levels, but offered a broad colour range. In closer detail, after squeezing the fruits, the preclarified juice at $\mathrm{pH} 6$ was adjusted to $\mathrm{pH} 4$ with citric acid followed by pectin hydrolysis with pectinase enzyme. Filtration gave the clarified juice that underwent the thermal preservation (pasteurization).

No browning was observed during juice production, including in the pasteurization step, due both to acidification and the specific amino acid composition of prickly pear. In place of beet root often suffering from geosmine (earth smell), the Opuntia red extract has several advantages such as neutral smell as well as the lack of nitrate. Similar good results were lately reported by scholars in Colombia studying the stability of Opuntia dillenii extracts added to foodstuffs at different $\mathrm{pH}$ and temperatures. ${ }^{37}$

Stintzing's team concluded that the process developed was suitable for being scaled up to industrial-scale production, especially because the cactus pear juice could be 
processed into concentrates and fruit powders which are easier to handle during transportation and storage. Indeed, the process has been adopted by industry, even though the juice extracted, thanks to its exceptional nutritional value, is not used for coloring purposes but rather sold as a nutraceutical product by a German company which offers the product to sports practitioners and for those who suffer from physical exhaustion. ${ }^{38}$ From a bioeconomy viewpoint, it is relevant to notice that the packaged juice was sold online by the end of 2017 at $€ 3.98 / 100 \mathrm{~mL}(€ 39.80 / \mathrm{L})$, showing the entity of the value addition process uograding the OFI fruit (currently traded in Italy at $€ 1.60 / \mathrm{kg}$ ). 


\section{Bioeconomy aspects}

Driven by a profound change in consumers' demand across the world, the food industry is redefining its supply aiming to promote healthfulness through its renewed products. It is enough to review the outcomes of a recent survey to learn that half of the US consumers have "changed their purchasing or engaged friends, family or coworkers as a result of reading or seeing something that examined the food system and/or commonly held beliefs about it"; and while taste and price consistently have been the top two factors that impact consumers' food and beverage purchases (84 percent and 71 percent respectively), healthfulness in 2016 almost entirely closed the gap with price, rising from 48 percent of consumers in 2006 to 64 percent ten years late, almost a 20 percentage-point increase. ${ }^{39}$

In China, the health food market was recently estimated to grow at an average annual rate of $10-15 \%$, with consumers' mind-set about health food gradually shifting from being seen as luxury goods to ordinary consumer products, and The Outline of the Programme for Food and Nutrition Development in China (2014-2020) mentions that Government will make the development of health food and nutrient fortified food one of its priorities. ${ }^{40}$

In Russia, in 2017 sales of organic food reached unprecedented levels (hitting \$250 million), with Government envisioning a future for the country becoming a leading supplier of healthy and high-quality food products in the world market in which their demand is steadily growing. ${ }^{41}$

These are just three selected examples of a widespread and rapidly increasing societal demand for natural ingredients replacing synthetic chemicals in food, beverage, cosmetic and nutraceutical products. As a result the global market of natural food colorants valued $\$ 1.31$ billion in 2015 is expected to grow at over 5\% annual rate between 2016 and $2021 .^{42}$

Growth is further compounded by the rising demand for processed and packaged food, driven by the growing urban population in huge economies, and by chemical 
technology advancements which are eventually making possible the incorporation of natural colours into all sort of food products (see above the case of the SupraRed colorant) without color degradation even during cooking or heat processing.

Compared to fresh produce, indeed, processed foods such as beverages, confectionary, bakery, meat, dairy and frozen products, intrinsically drive demand for colorants. Consumers like colors even more than taste, ${ }^{43}$ and since during processing the original color of food products turn out to lighten or to brown, colorants are added to restore the color boost consumer's preference. Accordingly, the EU legislation on food additive colours defines them as: "substances which add or restore colour in a food, and include natural sources which are normally not consumed as a foodstuff as such and not normally used as a characteristic ingredient in food". ${ }^{44}$

In general, betanin extracts are sold on the basis of betanin content. For example, by the end of 2017, powdered betanin ready for use as natural food colorant was sold online by an Italy's food colorant manufacturer at $€ 130 / \mathrm{kg} .{ }^{45}$ Globally, revenue from the beet root powder market (90,000 tonnes by 2016) was valued more than $\$ 15$ billion in 2016 , forecasted to expand at a compound annual growth rate of 5\% over the 2017-2027, ${ }^{46}$ to reach more than 1.1 million tonnes by 2027 . 


\section{Outlook and Conclusions}

Thanks to rapid recent progress in extraction, purification and stabilization technologies, betanin extracts from botanical sources can now be effectively used as red colorant in a broad variety of food and beverage products, including baked goods (and even at low usage rate, thereby reducing the overall cost of use). Furthermore, numerous new nutraceutical products will comprise among the active ingredients these powerful antioxidant, anti-inflammatory, anti-fatigue, and anti-carcinogenic agents.

To meet the increasing demand of betanin-based extracts of high quality, the old extraction processes based on solid-liquid extraction with acidic water will be replaced by advanced and entirely clean technologies such as supercritical fluid and solvent-free microwave-assisted extraction. ${ }^{6}$

One way to achieve the required cost reduction through enhanced supply is to expand betanin botanical sources from beet root to more abundant and faster growing plant and fruit sources, as it would happen sourcing the betalain from Opuntia fruit and, even better, from the fruit peel. Though containing a lesser betanin amount than beet root, ${ }^{47}$ sourcing this important colorant from Opuntia in addition to current industrial practice to extract the pigment from the Beta vulgaris L., would provide significant advantages. Contrary to beet root, mostly grown in the US, Russia, Germany, Poland and France, which slowly affords its high betanin content after two years of cultivation, the Opuntia plant is ubiquitous in semi-arid countries giving its numerous fruits twice a year between mid June and the late November.

Remarkably, when extracting betanin from the peel of both red and white OFI fruits, the mild extraction process applied using microwaves, and not even adding water, affords an integral extract whose other key components such as pectin and polyphenols are efficiently extracted and kept intact. ${ }^{48}$ This provides with unprecedented stability the new extracts, bottled in semi-transparent plastic bottles without even excluding air, whose deep 
red color is lasting unvaried for several months, thereby also addressing in a natural and straightforward way the key stability issue of betalain extracts for future applications. ${ }^{6}$

In conclusion, as the market for natural food colors continues to grow at quick rate, numerous new companies extracting said valued colorants from multiple botanical sources with the above mentioned green chemistry technologies will emerge. This study, in conclusion, will hopefully assist bioeconomy practitioners engaged in the transition from synthetic to natural red colorants beyond anthocyanins.

\section{Acknowledgements}

This article is dedicated to Professor Florian C. Stintzing, formerly at Hohenheim University, for all he has done to promote the bioeconomy of Opuntia based also on valorisation of its betalains. 


\section{References}

1. Panel on Food Additives and Nutrient Sources Added to Food, EFSA J. 2015, 13, 4318.

2. D. Strack, T. Vogt, W. Schliemann, Phytochemistry 2003, 62, 247-269.

3. D. McCann, A. Barrett, A. Cooper, D. Crumpler, L. Dalen, K. Grimshaw, E. Kitchin, K. Lok, L. Porteous, E. Prince, E. Sonuga-Barke, J. O. Warner, J. Stevenson, Lancet 2007, $370,1560-1567 .$.

4. University of Southampton, Food additives and behaviour in children, www.southampton.ac.uk/psychology/research/impact/food_additives.page.

5. European Parliament, Modernising the rules on food additives and labelling of azo dyes, Food safety, Briefing item, 3 July 2008.

6. N. Martins, C. Lobo Roriz, P. Morales, L. Barros, I. C. F. R. Ferreira, Food Funct. 2017, $8,1357-1372$

7. R. Ciriminna, A. Fidalgo, F. Meneguzzo, L. M. Ilharco, M. Pagliaro, ACS Sust. Chem. Engineer. 2016, 4, 643-650.

8. G. Bonat Celli, M. Su-Ling Brooks, Food Res. Int. 2017 100, 501-509.

9. G. W. Pucher, L. C. Curtis, H. B. Vickery, J. Biol. Chem. 1938, 123, 71-75.

10. M. Khairy, M. Ismael, R. M. El-Khatib, M. Abdelnaeem, M. Khalaf, Anal. Methods 2016, $8,4977-4982$

11. A. Gliszczyńska-Świgło, H. Szymusiak, P. Malinowska, Food Addit. Contam. 2006, 23, 1079-1087.

12. T. Esatbeyoglu, A. E. Wagner, V. B., Schini-Kerth, G. Rimbach, Mol. Nutr. Food Res. 2015, 59, 36-47.

13. M. Allegra, P. G. Furtmuller, W. Jantschko, M. Zederbauer, L. Tesoriere, M. A. Livrea, C. Obinger, Biochem. Biophys. Res. Commun. 2005, 332, 837-844.

14. R. A. Harmer, Food Chem. 1980, 5, 81-90.

15. S. Manchali, K. N. C. Murthy, S. Nagaraju, B. Neelwarne, Stability of Betalain Pigments of Red Beet. In: Red Beet Biotechnology, B. Neelwarne (Ed.) Springer, Boston: 2013; pp.55-74.

16. R. Cortez, D. A. Luna-Vital, D. Margulis, E. Gonzalez de Mejia, Compr. Rev. Food Sci. Food Saf. 2017, 16, 180-198.

17. J. Chandran, P. Nisha, R. S. Singhal, A. B. Pandit, J. Food Sci. Technol. 2014, 51, 2678-2684.

18. K. M. Herbach, M. Rohe, F. C. Stintzing, R. Carle, Food Res. Int. 2006, 39, 667-677.

19. A. M. Mayer, Phytochemistry 2006, 67, 2318-2331.

20. B. K. Tiwari, P. J. Cullen, Extraction of Red Beet Pigments. In: Red Beet Biotechnology, B. Neelwarne (Ed.) Springer, Boston: 2013; pp. 373-391.

21. F. C. Stintzing, R. Carle, Betalains in food: Occurrence, stability, and postharvest modifications, C. Socaciu (Ed.), Food Colourants: Chemical and Functional Properties, CRC Press, Boca Raton: 2008; pp. 227-299.

22. C. Sáenz, B. Cancino, P. Robert, Isr. J. Plant Sci., 2015, 60, 291-299

23. T. A. Garin, G. J. Vogel, US 4409254 A.

24. Z. Pietrzkowski, W. Thresher, WO/2008/094705.

25. B. Nemzer, Z. Pietrzkowski, A. Spórna, P. W. Stalica, W. Thresher, T. Michałowski,, S. Wybraniec, Food Chemistry 2011, 127, 42-53.

26. J. S. Van Hoorebeke, C. O. Trias, B. A. Davis, C. F. Lozada, G. A. Casazza, Sports 2016, $4,40$.

27. Z. Pietrzkowski, A. Spórna, P. Stalica, W. Tresher, R. Keller, R. Jimenez, T. Michałowski, S. Wybraniec, New Medicine 2010, 1, 12-17.

28. T. Clifford, B. Berntzen, G. W. Davison, D. J. West, G. Howatson, E. J. Stevenson, Nutrients 2016, 8, 506.

29. L. C. P. Goncalves, M. A. de Souza Trassi, N. B. Lopes, F. A. Dorr, M. T. dos Santos, J. W. Baader, V. X. Oliveira Jr., E. L. Bastos, Food Chem. 2012, 131, 231-238. 
30. K. M. Herbach, F. C. Stintzing, J. Food Sci. 2004, 69, C491-C498.

31. K. M. Herbach, F. C. Stintzing, Rapid Commun. Mass Spectrom. 2005, 19, 26032616.

32. D. Gebhardt, SupraRed - Consumer Insights on Natural Red Colors, slideshare.net, 22 August 2016.

33. J. Gelski, Naturally-sourced red color stands up to heat, foodbusinessnews.net, 18 July 2016.

34. G. A. Cardoso-Ugarte, M. E. Sosa-Morales, T.Ballard, A.Liceaga, M. F. San MartínGonzález, LWT Food Sci. Technol. 2014, 59, 276-282.

35. A. N. Nunes, C. S. Carmo, C. M. M. Duarte, $R S C$ Adv. 2015, 5, 83106-83114.

36. M. R. Moßhammer, F. C. Stintzing, R. Carle, Innov. Food Sci. Emerg. Tech. 2005, 6, 221-231.

37. M. J. Cejudo-Bastante, N. Hurtado, F. J. Heredi, Food Res. Int. 2015, 71, 91-99.

38. See at the URL: https://www.schoenenberger.com/de/schoenenberger/kaktusfeigenaturreiner-fruchtsaft-bio-02002417.

39. The International Food Information Council, 2016 Food and Health Survey, Washington: 2016.

40. HKTD Research, China's Health Food Market, 1 Aug 2017, HKTD Research, http://china-trade-research.hktdc.com

41. T. Higginson, Going green: organic food in Russia, food-exhibitions.com, 17 August 2017.

42. Zion Research, Natural Food Color Market (Carotenoid, Anthocyanin, Caramel) For Confectionary, Beverages, Dairy \& Frozen Products, Meat Products, Bakery: Global Industry Perspective, Comprehensive Analysis and Forecast, 2015-2021, Sarasota (FL): 2016.

43. J. Hoegg, J. W. Alba, J. Consumer Res. 2007, 33, 490-498.

44. U. Arlt, European Food Colour Legislation, natcol.org, 1 March 2010.

45. Rosso E162 barbabietola idrosolubile - Colore in polvere di estrazione, newdecorsart.it, (last time accessed, November 8, 2017).

46. Future Market Insights, Beetroot Powder Market: Global Industry Analysis (20122016) and Opportunity Assessment (2017-2027), London: 2017.

47. D. Butera, L. Tesoriere, F. Di Gaudio, A. Bongiorno, M. Allegra, A. M. Pintaudi, R. Kohen, M. A. Livrea, J. Agric. Food Chem. 2002, 50, 6895-6901.

48. R. Ciriminna, C. Danzì, G. Timpanaro, M. Locatelli, D. Carnaroglio, A. Fidalgo, A. Scurria, G. Avellone, L. M. Ilharco, M. Pagliaro, Preprints 2017, 2017100145 (DOI: 10.20944/preprints201710.0145.v1). 